\title{
Facile Synthesis and Electrochemical Study of CuO Thin Films for Hydrogen Peroxide Reduction in Alkaline Medium
}

\author{
Abderrazak Hamam $^{l, *}$, Charif Dehchar ${ }^{1}$, Mounira Maiza ${ }^{1}$, Imene Chikouche ${ }^{2}$, Halim Merabti ${ }^{1}$ \\ ${ }^{1}$ Research Center in Industrial Technologies CRTI, P.O. Box 64, Cheraga 16014, Algiers, Algeria \\ ${ }^{2}$ Laboratoire Croissance et Caractérisation de Nouveaux Semi-conducteurs, Université Ferhat Abbas, \\ Sétif-1, Algérie \\ "E-mail: hamam.abderrazak@yahoo.com
}

doi: $10.20964 / 2020.04 .15$

Received: 1 November 2019 / Accepted: 1 January 2020 / Published: 10 March 2020

In this work, we describe a simple electrochemical procedure for synthesis of structured copper (II) oxide $(\mathrm{CuO})$ films on copper $(\mathrm{Cu})$ substrate for the reduction of hydrogen peroxide $\left(\mathrm{H}_{2} \mathrm{O}_{2}\right)$. Films are grown in a single step by direct electrochemical oxidation of $\mathrm{Cu}$ foil from a solution of $5 \mathrm{M} \mathrm{KOH}$ using cyclic voltammetry method. Scanning electron microscopy images reveal that $\mathrm{CuO}$ is uniformly grown on the surface of the substrate and presents a lawn-like microstructure. Electrocatalytic activity of the electrode toward hydrogen peroxide reduction is investigated by cyclic voltammetry and chronoamperometry in 3.0 M KOH solution. The prepared electrode exhibits remarkable catalytic activity, good reproducibility and stable electrochemical response.

Keywords: Copper oxide; electrocatalysis; hydrogen peroxide; thin film; cathode materials

\section{FULL TEXT}

(C) 2020 The Authors. Published by ESG (www.electrochemsci.org). This article is an open access article distributed under the terms and conditions of the Creative Commons Attribution license (http://creativecommons.org/licenses/by/4.0/). 